\title{
BASES SOCIAIS, ATITUDINAIS E COMPORTAMENTAIS DO APARTIDARISMO BRASILEIRO ${ }^{1}$
}

[1] Este paper é resultado do projeto de pesquisa intitulado "Os determinantes do ativismo partidário e do comparecimento eleitoral na América Latina", desenvolvido com apoio financeiro do CNPq/CAPES.
JULIAN BORBA

ÉDER RODRIGO GIMENES

EDNALDO APARECIDO RIBEIRO

\section{RESUMO}

Pesquisas empreendidas em democracias avançadas alertam para a expansão de um novo perfil de eleitor, apartidário, caracterizado por alta mobilização cognitiva, forte apoio à democracia, posicionamento crítico em relação às instituições hierárquicas e preferência por formas diretas de ação política. Alguns pesquisadores preocupados com esse fenômeno tem procurado identificar os contornos fundamentais dessa cidadania crítica, inclusive propondo classificações e tipologias para esses novos eleitores. Entre esses, Russell Dalton se destaca ao combinar variáveis de mobilização cognitiva e simpatia partidária para a definição de quatro perfis básicos (independentes apolíticos, partidários rituais, partidários cognitivos e apartidários) e discute as consequências de cada um deles para a democracia atual. Apesar de plausível no contexto das democracias consolidadas, com significativos estoques de apoio difuso ao regime, tais perfis podem não ser compatíveis com o contexto das jovens democracias, nas quais a cidadania crítica nem sempre é acompanhada de democratismo consistente em razão da curta experiência com o regime. O objetivo do artigo, desta forma, é avaliar a pertinência dessa classificação para esse contexto diverso, através da identificação dos condicionantes sociais, atitudinais e comportamentais de cada um dos quatro tipos de eleitor entre o público brasileiro.

PALAVRAS-Chave: apartidarismo, cultura política, democracia, Brasil.

\section{ABSTRACT}

Researches developed in advanced democracies have warned of the spread of a new profile of voters, the apartisan, characterized by high cognitive mobilization, strong support for democracy, critical position in relation to hierarchical institutions and preference for direct forms of political action. Some researchers interested in this phenomenon have been seeking to identify the fundamental outlines of this critical citizenship, including proposing classifications and typologies for these new voters. Among these, Russell Dalton stands combining variables of cognitive mobilization and partisan sympathy to define four basic profiles (independent political, ritual partisans, cognitive partisans and apartisans) and discusses the consequences of each of them to the actual democracy. Although plausible in the context of consolidated democracies, with significant stocks of diffuse support for the regime, such profiles can be not compatible with the context of young democracies, in which the critical citizenship is not always accompanied by consistent democratism because of the short experience with the regime. The objective of this article, therefore, is to assess the pertinence of this classification for this different context, by identifying the social, attitudinal and behavioral determinants of each of the four types of voters among the Brazilian public.

KEYWORDS: apartisanship, political culture, democracy, Brazil. 
No debate contemporâneo sobre os padrões de cidadania política nos regimes democráticos, a distinção entre modalidades tradicionais e inovadoras de engajamento cívico se destaca. De forma geral, as pesquisas recentes têm apontado para um quadro de redução do envolvimento nesse primeiro grupo de canais (Dalton; Wattenberg, 2002; Putnam, 2003), com destaque aos partidos políticos, e o avanço do ativismo por canais que alguns chamam de não convencionais, como os diferentes tipos de protesto (Inglehart e Catterberg, 2002; Catterberg, 2003; Welzel, Inglehart e Deustch, 2005; Norris, 2007).

Focalizando especificamente a situação dos partidos políticos, pesquisadores como Russell Dalton (2013) têm se dedicado à discussão sobre essa mudança no padrão de interações entre cidadãos e instituições. A partir de dados que apontam para o crescente distanciamento dos eleitores em relação aos partidos, esses pesquisadores têm diagnosticado a crise dessas instituições, caracterizada principalmente pelo declínio das taxas de filiação em países europeus, nos Estados Unidos e em algumas nações latino-americanas.

Boa parte desses diagnósticos atribui a causalidade do fenômeno a fatores estruturais, em especial à reorganização funcional dos partidos políticos diante das alterações em seu relacionamento com o Estado, que medeia e controla a competição eleitoral. Entretanto, há que considerar a relevância de fatores exógenos às instituições, em especial o refinamento cognitivo dos cidadãos (Mair, 2003; Witheley, 2011; Mayer, 2011; Dalton, 2013). Sob essa perspectiva, o afastamento dos eleitores em relação aos partidos não seria tratado apenas como consequência, mas também como fator causal do declínio dos partidos políticos enquanto instituições representativas.

É nesse sentido que Dalton (2013) levanta a tese de que os Estados Unidos e as demais democracias avançadas estariam presenciando a expansão de um novo tipo de eleitor, que o autor denomina apartidário. Tal eleitorado seria constituído por indivíduos dotados de alta cognição e se caracterizaria por uma base atitudinal de forte apoio à democracia, posicionamento crítico em relação às instituições hierárquicas e preferência pelas formas diretas de ação política. Entre as consequências de tal constatação advêm tanto alterações no comportamento político do eleitorado quanto mudanças na estrutura do jogo político e no posicionamento de candidatos e partidos, no período eleitoral e para além dele.

As características peculiares desse eleitor desencantado com as instituições tradicionais da democracia fazem com que o cenário contemporâneo não seja interpretado como negativo ou potencialmente perigoso para a estabilidade democrática. Pelo contrário, esse 
novo eleitor é visto como agente de uma nova cidadania crítica, totalmente congruente com processos de aprofundamento dessa forma de governo, já que são portadores de valores fortemente democráticos e estariam orientados para formas de atuação política mais horizontalizadas e baseadas na autoexpressão (Dalton, McAllister e Wattenberg, 2003; Dalton, 2013).

Essa interpretação é plausível nos contextos das democracias consolidadas com longo histórico de estabilidade política, sobretudo em razão dos consideráveis estoques de legitimidade construídos ao longo de gerações socializadas sob a vigência de instituições democráticas.Em cenários distintos, como os das chamadas jovens democracias, todavia, a sua aplicabilidade merece ser ao menos problematizada. A adesão normativa entre cidadãos dessas nações com baixa tradição democrática tende a ser mais frágil, logo, os efeitos da desafeição partidária podem ser mais deletérios, sendo plausíveis hipóteses de efeitos desestabilizadores (Torcal e Montero, 2006; Ribeiro, 2011).

É nesse debate sobre efeitos positivos e negativos da desafeição dos cidadãos a essas instituições representativas fundamentais dos sistemas políticos contemporâneos que o presente trabalho se insere. Nosso objetivo central é apresentar resultados de investigação que procurou avaliar os possíveis efeitos desse afastamento sobre regimes de baixa tradição democrática, tomando o caso brasileiro como objeto empírico. Nossa intenção é verificar se o fenômeno do apartidarismo pode ser considerado como indicativo de sofisticação política do eleitorado, e, portanto, congruente com o aprofundamento do processo democrático, ou se, contrariamente, tem sido acompanhado de afastamento da vida política e de redução da adesão normativa a essa forma de governo.

Tendo em vista essa intenção, dividimos o texto em quatro seções, além desta introdutória. Inicialmente apresentamos breve revisão sobre a literatura internacional que tem discutido esse novo padrão de cidadania. Posteriormente, adotando um modelo específico de construção de perfis de eleitorado, procuramos identificar o quadro da desafeição dos cidadãos brasileiros em relação aos partidos. $\mathrm{Na}$ terceira seção procuramos testar a hipótese da associação desse perfil desafeto com um conjunto de valores e atitudes pró-democracia. Por fim, nas considerações finais avaliamos as implicações dos resultados encontrados para o cenário democrático nacional, bem como para as interpretações correntes sobre a chamada cidadania crítica.

\section{O APARTIDARISMO E SEUS EFEITOS}

Pesquisadores que têm identificado a emergência de uma cidadania crítica nos países de democracia consolidada têm apontado a sofisticação cognitiva como principal componente desse novo padrão 
de cidadania. Parte considerável dessa literatura internacional tem evidenciado o aumento dos níveis educacionais no pós-guerra como fator condicionante da identificação desses cidadãos mais engajados (Dalton, 1984; Inglehart, 1990). Na verdade, o fator educacional encontra-se amplamente associado ao conhecimento político, à participação política em partidos, em atividades voluntárias e em sindicatos e ainda a outras formas de engajamento político.

Pesquisas empíricas desenvolvidas na década de 1960 já indicavam que os cidadãos instruídos são mais ativos politicamente em suas comunidades, sendo mais informados sobre a política e mais tolerantes (Almond e Verba, 1989 [1963]). Da mesma maneira, trabalhos mais recentes têm confirmado as evidências de que habilidades cognitivas e educação são fundamentos para o engajamento político, envolvendo os cidadãos em eleições, ações diretas sobre campanhas políticas e em partidos (Inglehart, 1990; Dalton, 2006;2007).

Tais argumentos compõem a base do modelo de engajamento cognitivo, segundo o qual a participação partidária é uma forma de mobilização mais frequente entre cidadãos com maior escolaridade, maior sentimento de eficácia política subjetiva, maior relacionamento com assuntos políticos por meio de conversas, acesso a informações, ativismo eleitoral e participação em associações voluntárias ${ }^{2}$. O referido modelo argumenta que a participação política de um indivíduo é motivada por sua capacidade e vontade para processar e compreender informações relacionadas à política, sendo tais indivíduos mais capazes de influenciar politicamente por meio de seu envolvimento em grupos de interesses e partidos. Tais cidadãos possuem ainda habilidades para constituir um eleitorado mais crítico em relação ao processo eleitoral e ao governo (Norris, 2000).

Tendo como principal embasamento a teoria da mobilização cognitiva, Dalton (2013) dedicou-se à identificação do perfil do eleitorado norte-americano atual. Em sua avaliação sobre o crescente número de eleitores independentes em termos partidários e os fatores que contribuem para essa expansão, o autor identifica o perfil dos "novos independentes" (jovens, mais instruídos e interessados por política, sem alianças partidárias como aquelas desenvolvidas na geração de seus pais) e os diferencia daqueles mais velhos, entre os quais são arraigadas identificações como "democrata" ou "republicano".

Com vistas à identificação de diferentes perfis de eleitores, Dalton (2013) criou um índice de mobilização cognitiva, a partir do qual apontou quatro padrões de mobilização distintos. A construção dos perfis baseou-se exclusivamente em três variáveis: escolaridade, interesse por política e simpatia partidária. Segundo o autor, educação e interesse por política compõem o indicador de mobilização cognitiva dos indivíduos, o qual é combinado com a medida de simpatia partidária.

\footnotetext{
[2] Também se destacam no modelo idade e interesse por política. No entanto, a literatura aponta uma contradição entre seus resultados, visto que, enquanto Dalton (2013) destaca que grupos etários mais jovens apresentam níveis mais elevados de educação e, não raras vezes, interesse por política menor que entre outras faixas etárias, Inglehart afirma que indivíduos pós-materialistas seriam mais interessados por política, especialmente os jovens.
} 
No primeiro perfil, dos independentes apolíticos, encontraríamos indivíduos pouco sofisticados cognitivamente e sem ligação com os partidos. São eleitores pouco preocupados com as questões políticas e com os candidatos, entre os quais a previsibilidade do comparecimento e da escolha eleitoral é difícil. Por sua vez, os partidários rituais são guiados pela identidade partidária e possuem conhecimento limitado sobre questões políticas. $\mathrm{Na}$ ausência de recursos cognitivos, apoiam o partido nas eleições por meio da campanha e do voto. Os partidários cognitivos também são eleitores vinculados a partidos políticos, mas diferem do grupo anterior pelo fato de que sua participação nas referidas instituições se deve a seu refinamento político, ou, nos termos de Dalton (2013), à sua cognição. Por fim, os apartidários são indivíduos que possuem refinamento cognitivo e que orientam sua atuação política por meio de suas competências, sem dependência de rótulos partidários para a avaliação e escolha de seus candidatos.

Considerando tais perfis, Dalton (2013) conduz testes que sugerem que quanto maior a cognição dos indivíduos, maior a sua busca por informações sobre temas políticos e seu apoio a valores democráticos. Além disso, o nível de participação política em modalidades não relacionadas às instituições tradicionais de representação também aumenta.

Sobre a avaliação dos candidatos e a escolha dos votos, Dalton (2013) encontrou resultados que lhe permitiram inferir que os eleitores independentes apolíticos são menos propensos a votar e que, quando o fazem, agem por meio de recursos de difícil previsão, extrema subjetividade e ausência de racionalidade, típica de eleitores com pouca ou nenhuma cognição política. O voto dos partidários rituais, por sua vez, seria uma escolha baseada prioritariamente em seu processo de socialização, sem influência nem tentativa racional de valoração dos candidatos ou de suas propostas ou programas políticos. Já os partidários cognitivos realizariam suas escolhas eleitorais baseados tanto nos vínculos partidários dos candidatos quanto nas propostas apresentadas por eles e por seus partidos, de modo que, ainda que sejam muito propensos a votar nos candidatos dos partidos com os quais mantêm laços partidários, existe a possibilidade de alteração do voto por conta do refinamento cognitivo dos indivíduos. Entretanto, por se tratar de um sistema político em que os votos são bipolarizados (democratas/republicanos), a maioria dos partidários cognitivos opta por não votar quando as propostas de seu candidato ou partido não lhe agradam, de modo a não contribuir, por consequência, para a eleição do adversário político de seu partido. Por fim, o eleitor apartidário promove suas escolhas por meio da análise e avaliação de candidatos e propostas, em conformidade com seus interesses e sem preocupação com legendas. 
Os resultados apresentados por Dalton (2013) o levam a considerar que o aumento dos níveis de ensino, do acesso à informação política e do entendimento quanto ao papel das instituições é capaz de produzir um processo de mobilização cognitiva que pode ampliar as habilidades políticas e recursos do cidadão médio. Dessa maneira, a mobilização cognitiva teria potencial para mudar o processo eleitoral, tornando-o mais próximo ao ideal da teoria democrática, com eleitores capazes de fazer julgamentos independentes dos candidatos e das questões do momento.

Em termos dos efeitos mais amplos para o futuro da democracia, a emergência desse novo padrão de cidadania não deveria ser entendida como sinal de fragilidade ou indicador de redução de legitimidade, pois a base atitudinal e valorativa desse indivíduo crítico seria compatível com processos de aprofundamento dessa forma de governo. Em síntese, o cidadão crítico em relação aos partidos não se coloca contra a democracia, apenas identifica que as instituições democráticas tradicionais (entre as quais os partidos) não correspondem ao que se espera delas, sem com isso se desencantar com o ideal democrático como um todo.

Como dissemos no início do texto, esse é o quadro apontado por autores como Dalton (2013) para o contexto das nações com histórico democrático considerável, o que consideramos bastante plausível. O contexto das nações que experimentaram suas transições políticas apenas na Terceira Onda, todavia,é bastante distinto e merece atenção especial quando se trata da avaliação dos potenciais efeitos negativos do apartidarismo. Na próxima seção começamos a apresentar os resultados de nosso esforço de análise nessa direção, avaliando como os cidadãos nacionais se distribuem entre os perfis de relacionamento com as instituições partidárias.

\section{PARTIDÁRIOS E APARTIDÁRIOS NO BRASIL}

A trajetória do sistema partidário brasileiro é de bastante instabilidade em razão de inconstâncias no padrão de organização dos partidos e de interrupções nas experiências democráticas vivenciadas durante o século passado. Entre o eleitorado, contudo, o período democrático recente é marcado por certa manutenção dos níveis de identificação partidária. Nesse sentido, ainda que o partidarismo não esteja se fortalecendo como esperava Kinzo (2007), são muitos os estudos cujos resultados demonstram a relevância da identificação e da simpatia partidária ao comportamento político dos brasileiros (Carreirão e Kinzo, 2004; Carreirão, 2007; 2008; Veiga, 2007; 2011; Ribeiro, Carreirão e Borba, 2011; Samuels; Zucco Junior, 2012). 
[3] O material empírico utilizado em todos os testes foi produzido pelo Latin American Public Opinion Project, coordenado pela Universidade de Vanderbilt (Texas) em suas ondas de 2002, 2006, 2008 e 2012. Informações técnicas sobre as amostras e os procedimentos de coleta de dados para o caso nacional podem ser obtidas diretamente no endereço eletrônico do projeto: www.vanderbilt. edu/lapop/.

[4] Informações técnicas sobre as variáveis e recodificações encontram-se no apêndice.
Considerando os bancos de dados coletados pelo Latin American Public Opinion Project(LAPOP) 3 no período entre 2006 e 2012 , esta seção tem por finalidade estabelecer um quadro geral do padrão de relações estabelecidas entre os cidadãos brasileiros e os partidos políticos, baseado na tipificação estabelecida por Dalton (2013). Como mencionado anteriormente, o modelo proposto por esse autor se fundamenta na combinação das variáveis escolaridade e interesse por política, para compor a medida de cognição, e na medida de simpatia partidária como indicador de partidarismo ${ }^{4}$. Sendo assim, iniciamos a composição desse quadro nacional pela identificação da evolução dessas medidas ao longo dessa curta série histórica selecionada.

O Gráfico 1 apresenta as alterações nos níveis de escolaridade dos brasileiros segundo dados do LAPOP, os quais corroboram as informações oficiais da Pesquisa Nacional por Amostra de Domicílios (PNAD), do Instituto Brasileiro de Geografia e Estatística (IBGE), referentes ao período de 2006 a 2011 . Em termos gerais, é possível verificar uma melhoria no nível de escolarização dos brasileiros no período recente, com redução no percentual das categorias de menor escolaridade e ampliação dos contingentes das categorias com mais anos de estudo. Comparando-se os resultados referentes a $2006 \mathrm{e}$ 2012 , constatamos decréscimo de aproximadamente 13\% no total de brasileiros sem instrução ou com até ensino fundamental completo, ao passo que as demais faixas de escolaridade sofreram incrementos de 7,6\% para aqueles com até ensino médio completo, de 2,4\% entre os que possuem ensino pós-médio ou superior incompleto e de 3,2\% entre os brasileiros com ensino superior completo ou pós-graduação.

\section{Gráfico I}

Evolução da escolaridade dos brasileiros (2006-2012)

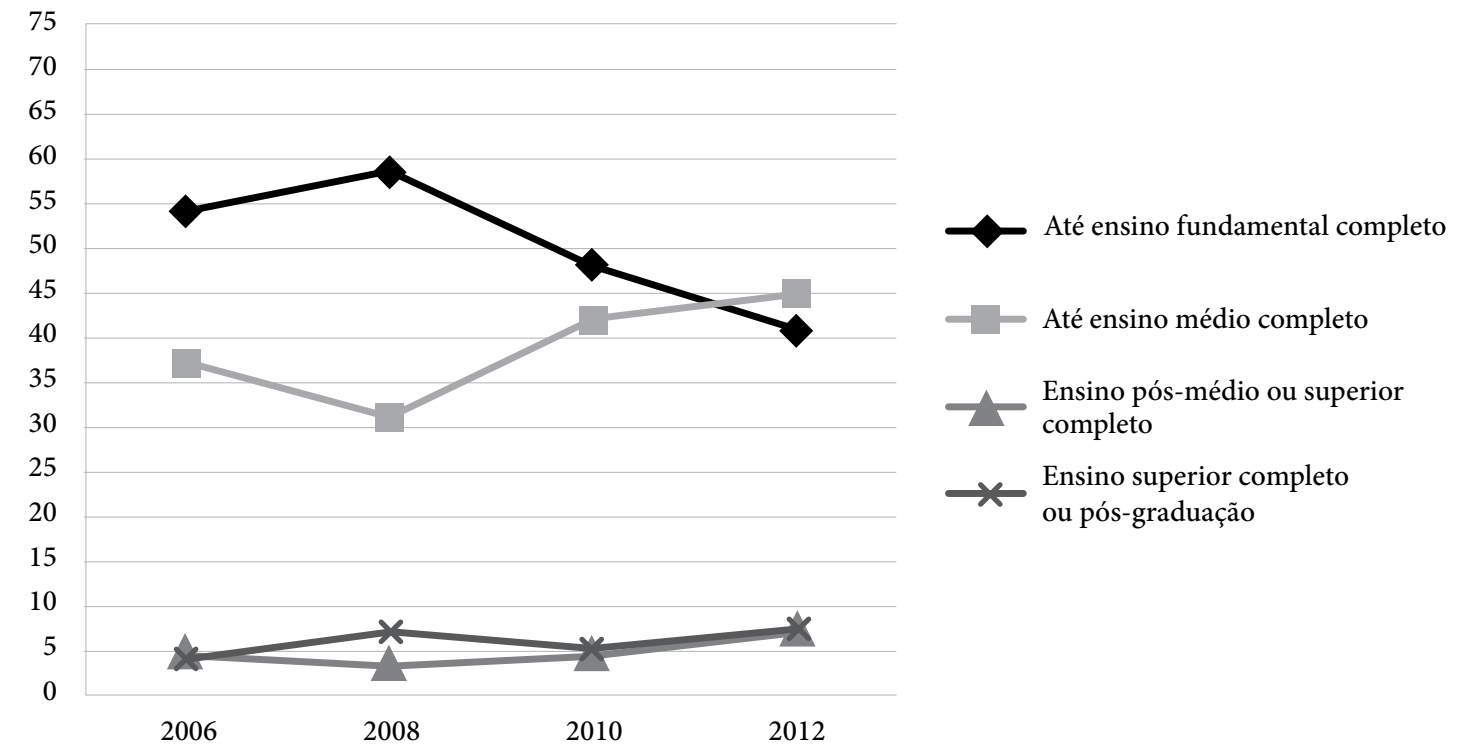


De maneira contrária, em se tratando do interesse por política, verificamos uma redução no contingente de interessados entre 2006 e 2008 , conforme aponta o Gráfico 2. Na primeira onda do LAPOP analisada, o percentual de cidadãos algo ou muito interessados por política atingiu o maior somatório do período, com 36,4\% de respostas, mas logo no período seguinte houve brusca alteração do cenário, marcado, principalmente, pelo acréscimo percentual de brasileiros que se declararam pouco interessados por política e decréscimo entre aqueles com algum interesse.

\section{Gráfico 2}

Evolução do interesse dos brasileiros por política entre 2006 e 2012

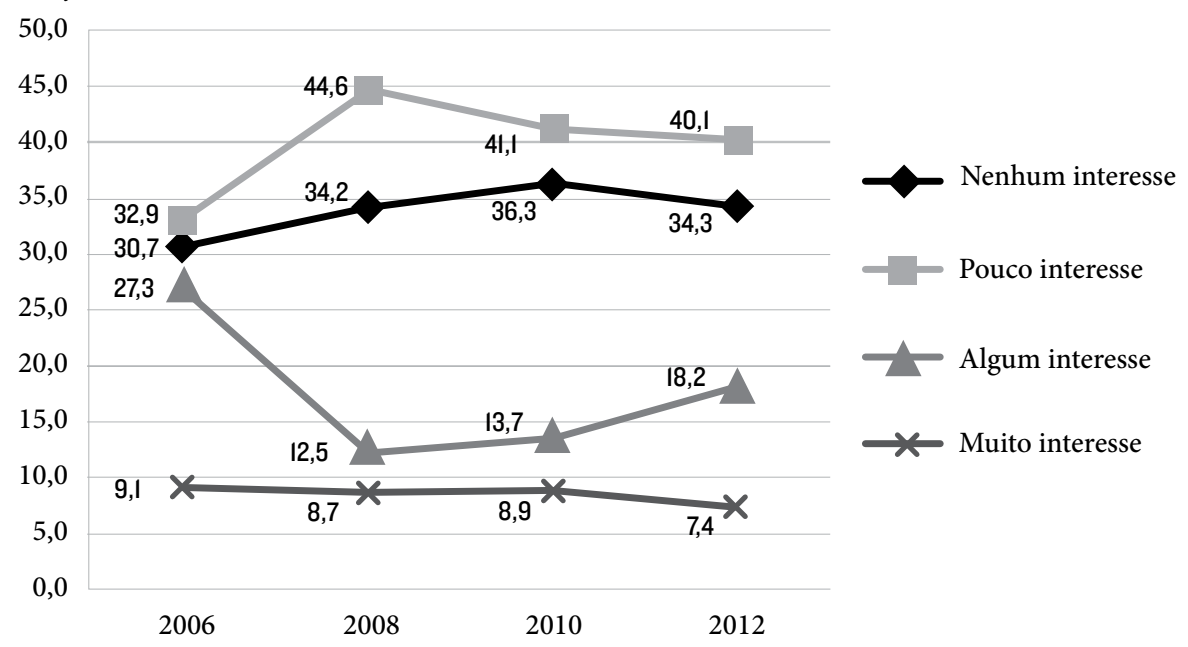

Fonte: LAPOP (2006; 2008; 2010; 2012).

Conforme mencionado anteriormente, a medida de mobilização cognitiva utilizada por Dalton (2013) consiste no somatório dos recursos escolaridade e interesse por política. A construção de tal índice considera ambas as variáveis como escalas de 4 pontos, cuja soma resulta numa medida de 7 pontos, distribuídos entre 2 e 8 . O corte da escala em duas faixas define que indivíduos localizados entre os pontos 2 e 5 possuem baixa mobilização cognitiva, ao passo que aqueles entre os pontos 6 e 8 dispõem de alta mobilização cognitiva. Os resultados referentes a tal índice seguem expostos na Tabela 1.

Tabela I

Mobilização cognitiva dos brasileiros entre 2006 e 2012 (\%)

\begin{tabular}{c|c|c|c|c}
\hline Perfil & 2006 & 2008 & 2010 & 2012 \\
\cline { 2 - 3 } \cline { 5 - 5 } Baixa & 90,9 & 90,2 & 90,2 & 88,5 \\
\hline Alta & 9,1 & 9,8 & 9,8 & 11,5 \\
\hline TOTAL & 100,0 & 100,0 & 100,0 & 100,0 \\
\hline
\end{tabular}

Fonte: LAPOP (2006;2008; 2010; 2012). 
Os resultados indicam que, diferentemente das variáveis das quais decorre o índice, este não sofreu oscilações negativas no período, ou seja, não foi identificada redução do perfil de alta cognição. Considerando a elevação do nível de escolarização dos brasileiros, verificada também na pesquisa LAPOP utilizada como medida de escolaridade neste artigo (ver nos Anexos), e a redução de seu interesse por política entre 2006 e 2012 , a variação positiva da mobilização cognitiva no período confirma a afirmação de Dalton (2013) de que a educação é o cerne de seu modelo de análise.

Com relação à simpatia partidária, os dados coletados pelo LAPOP demonstram maior variação no biênio 2006-2008, quando comparado com os períodos 2008-2010 e 2010-2012.

Tabela 2

Simpatia partidária dos brasileiros entre 2006 e 2012 (\%)

\begin{tabular}{|c|c|c|c|c|}
\hline Perfil & 2006 & 2008 & 2010 & 2012 \\
\hline Sem simpatia partidária & 65,2 & 74,6 & 70,1 & 69,5 \\
\hline Com simpatia partidária & 34,8 & 25,4 & 29,9 & 30,5 \\
\hline TOTAL & 100,0 & 100,0 & 100,0 & 100,0 \\
\hline
\end{tabular}

Fonte: LAPOP (2006; 2008; 2010; 2012).

Pode-se notar diminuição do partidarismo no primeiro biênio e aumentos no segundo e no terceiro. Apesar da recuperação em 2010 e 2012, o contingente de partidários não retornou ao patamar inicial de 2006 . É preciso, todavia, considerar as margens de erro de cada sondagem, já que em alguns casos a variação pode se dever a esse fator e não à efetiva mudança nas atitudes dos brasileiros. Para 2006, 2008 e 2012 essa margem é de 2,5 pontos percentuais, enquanto para 2010 é de 1,79. Logo, considerando essas informações, apenas entre 2010 e 2012 as diferenças são menores do que a amplitude da estimativa intervalar, o que nos obriga a falar de estabilidade nesse período entre as duas últimas pesquisas. De qualquer forma, essa consideração não altera a conclusão geral de uma queda na metade dessa curta série histórica e uma recuperação ainda tímida no final.

A partir de dados dos últimos Estudos Eleitorais Brasileiros (Esebs), Veiga (2007) e Ribeiro, Carreirão e Borba (2011) indicam que a redução da identificação partidária verificada a partir do pleito de 2006 teve no conjunto de denúncias de corrupção relacionadas ao Partido dos Trabalhadores (PT), ocupante da Presidência da República no período, um dos fatores responsáveis pelo decréscimo de identificação partidária entre os brasileiros. Considerando a impossibilidade de comparação das taxas de simpatia partidária no Brasil em razão da ausência de dados do LAPOP coletados no país anteriores a 
2006, assumimos a hipótese acima, de modo que, nesse sentido, os dados referentes aos períodos seguintes indicam que a retomada do crescimento do partidarismo após a crise que se refletiu nos valores encontrados em 2008 vem ocorrendo, porém de maneira mais lenta que a queda. Destaque-se ainda que o percentual de brasileiros que deixaram de ser partidários e passaram a não partidários foi de 4,33\% no somatório do período.

A construção dos perfis do eleitorado desenvolvida por Dalton (2013), como já mencionamos, consiste na relação entre mobilização cognitiva e simpatia partidária, conforme exposto na Tabela 3. A combinação da ausência de simpatia por algum partido com a identificação de alto índice de mobilização cognitiva caracteriza os indivíduos classificados como apartidários. Aqueles que se identificam com partidos e também gozam de alta cognição são considerados partidários cognitivos. Cidadãos simpáticos a algum partido que se caracterizam ainda por baixa mobilização cognitiva são identificados como partidários rituais. Por fim, os que não nutrem simpatia por nenhum partido e apresentam baixa cognição são denominados independentes apolíticos.

Tabela 3

Índice de mobilização cognitiva

\begin{tabular}{|c|c|c|}
\hline & Mobilização partidária & \\
\hline Mobilização cognitiva & Sem identificação partidária & $\begin{array}{c}\text { Fraca/forte identificação } \\
\text { partidária }\end{array}$ \\
\hline Alta & Apartidários & Partidários cognitivos \\
\hline Baixa & Apolíticos independentes & Partidários rituais \\
\hline
\end{tabular}

Fonte: adaptado de Dalton (2013, p. 40).

O Gráfico 3 apresenta a evolução desses perfis entre o público nacional no período analisado e aponta ligeiras variações. Ainda que em termos absolutos as alterações sejam discretas, evidencia-se a redução dos partidários rituais no Brasil entre 2006 e 2012. No mesmo período, os demais perfis sofreram acréscimos. Cabe destacar que, ainda que correspondam a apenas $6,3 \%$ do eleitorado brasileiro, os apartidários apresentaram os resultados mais estáveis no período, em decorrência das elevações nos biênios 2006-2008 e 2010-2012 e considerada ainda a manutenção entre 2008 e 2010.

Ademais, cabe ressaltar que os percentuais de partidários cognitivos e apartidários no Brasil são muito próximos. Apenas quando da primeira onda do LAPOP, em 2006, foram identificados mais partidários cognitivos que apartidários, e a partir de 2008 o percentual de indivíduos classificados no segundo perfil se sobrepõe ao do primeiro. 


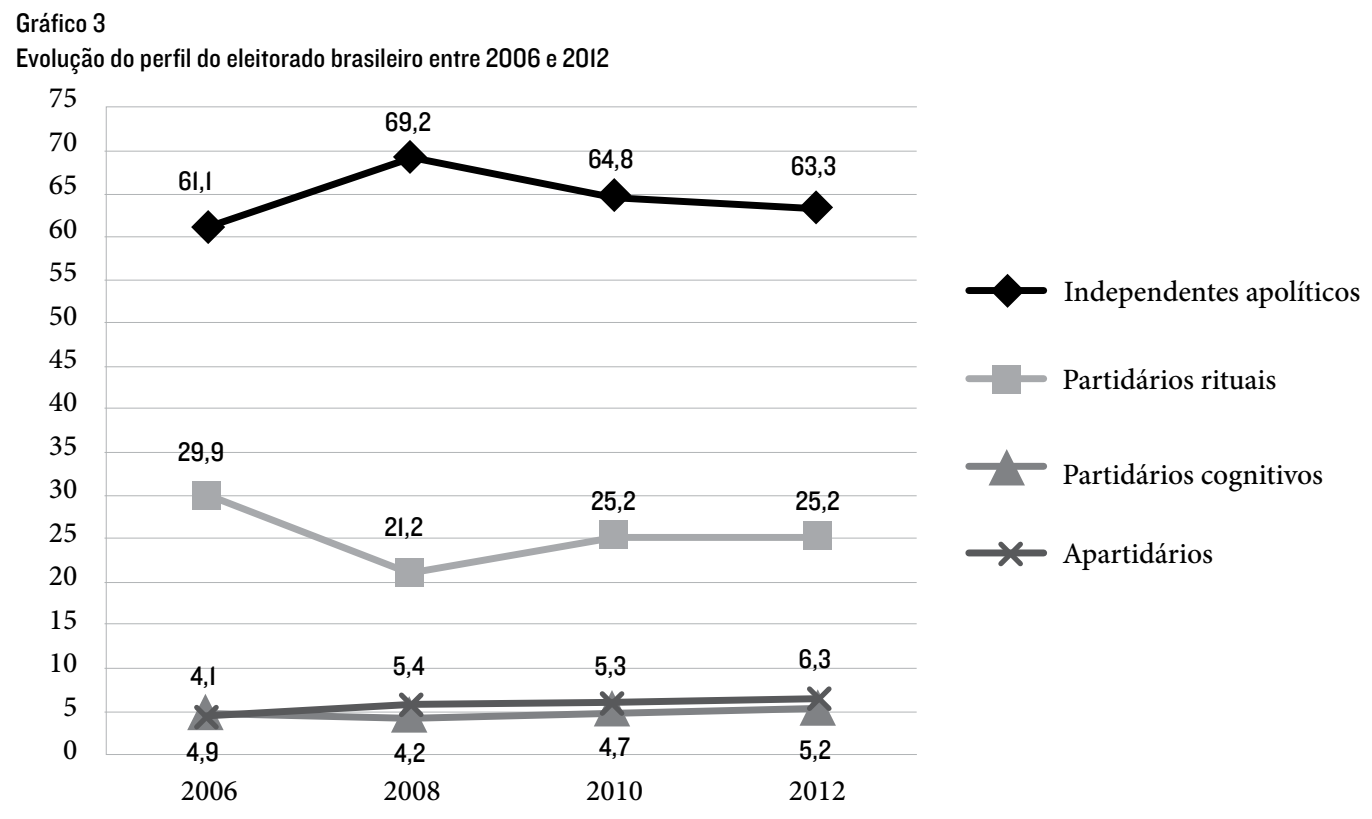

Fonte: LAPOP (2006; 2008; 2010; 2012).

[5] Tal reflexão é objeto de discussão dos autores deste artigo, que almejam, para trabalhos futuros, a proposição de uma medida alternativa de mobilização cognitiva para brasileiros e latino-americanos.

[6] Informações descritivas sobre a distribuição percentual dos eleitores entre as variáveis independentes encontram-se nos Anexos.
É importante ressaltar que, apesar de o índice de engajamento cognitivo utilizado para a composição dos perfis ter sido validado por Dalton no contexto norte-americano, autores como Alaminos e Penalva (2012) o criticam em razão do uso da variável escolaridade na composição, por seu papel enquanto preditor do interesse por política, eficácia política subjetiva, participação cívica e contestatória etc. Além disso, faz-se necessário refletir sobre a transposição do referido índice para democracias em consolidação, como é o caso brasileiro, o qual se caracteriza por baixo percentual de indivíduos com alta escolarizaçãos. Não desconhecemos nem desvalorizamos tais críticas, entretanto, acreditamos que é importante partir dessa medida e da tipologia gerada para verificamos efetivamente quais são os seus rendimentos no contexto das jovens democracias.

Buscando compreender melhor quem são os indivíduos que se reúnem nos diferentes perfis, empreendemos análises multivariadas para identificar os seus principais preditores. Os modelos tomaram como variáveis independentes alguns atributos sociais e demográficos, quais sejam: sexo, idade, etnia, estado civil eárea de residência ${ }^{6}$. Considerando que a medida de mobilização cognitiva proposta por Dalton (2008;2013) é constituída pela combinação entre escolaridade e interesse por política, não incluímos em nossos testes a variável identificação ideológica, uma vez que Carreirão (2002) indica que esta, ao menos no que se refere ao comportamento eleitoral dos brasileiros, está diretamente associada ao nível de escolarização. 
A variável sexo foi codificada com vistas à identificação da ausência/presença do atributo masculino, uma vez que estudos recentes têm identificado a sobrerrepresentação masculina nos meios políticos em democracias contemporâneas, um indicativo de desigualdade política entre homens e mulheres num cenário global (Ribeiro, 2011a; Whiteley, 2011; Van Biezen, Mair e Poguntke, 2012). No caso específico desta pesquisa nos interessa identificar se essa desigualdade se reproduz no padrão de interação entre cidadãos e partidos.

Por sua vez, a variável idade foi inserida para possibilitar a identificação de possíveis efeitos geracionais e de ciclos de vida nessa relação, tais como os verificados por Inglehart (1990) e O'Neill (2001).É preciso, entretanto, considerar que alguns autores têm alertado para o fato de que os indivíduos participam menos quando são muito jovens e muito velhos, o que não permitiria um relacionamento linear entre o ativismo partidário e a idade dos eleitores (Witheley, 2011; Van Biezen, Mair e Poguntke, 2012; Dalton, 2013)7.

Em se tratando do estado civil, trabalhamos com o binômio casado/não casado, adotando o argumento de Dalton (2013), que associa tal característica à idade e afirma que, num ciclo de vida normal, o aumento da idade está associado ao desenvolvimento de uma carreira e à propensão à constituição de uma família, fatores que tendem a aumentar a probabilidade de os indivíduos se engajarem em atividades relacionadas à política, como os partidos.

Já com relação às demais variáveis inseridas nos testes, levando em conta a ausência, no survey do LAPOP, de outras medidas relativas ao modelo socioeconômico (a saber, renda, e o fato de escolaridade fazer parte da medida utilizada para compor os perfis), consideramos que etnia e local de residência são boas proxys de recursos, tendo em vista a existência de forte associação entre renda e raça e também diferenças significativas entre eleitores urbanos e rurais, conforme apontam Reis e Castro (1992). Tais autores afirmam ainda a relevância de considerar a "[...] maneira pela qual o aspecto geográfico ou regional se articula com os componentes mais sociológicos do conceito de centralidade" (Reis e Castro, 1992, p. 127), o qual é perpassado por variáveis relacionadas à posição social dos indivíduos nas estruturas sociais (Milbrath e Goel, 1965).
[7] Uma alternativa para minimizar tal problema é a utilização da forma quadrática dessa variável (idade + idade $^{2}$ ). Realizamos testes com a variável idade em sua medida original (contínua) e em sua forma quadrática, porém os resultados foram semelhantes. Dessa maneira, optamos pela manutenção da variável em seu formato original, a fim de testar a existência de linearidade sobre os perfis dos eleitores brasileiros. 
Tabela 4

Preditores dos perfis do eleitorado brasileiro

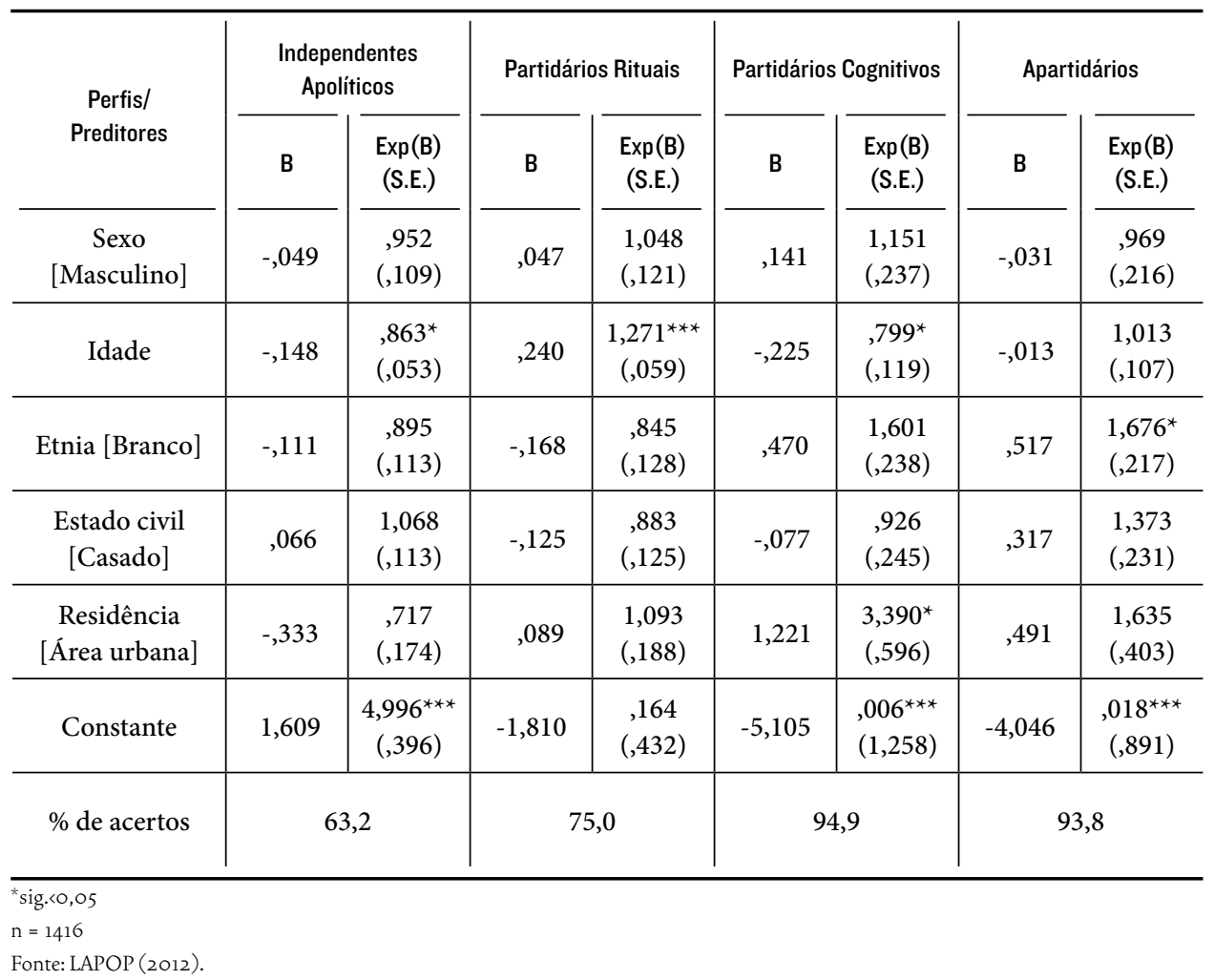

Em se tratando de preditores dos perfis, verificamos que os atributos sociais e demográficos testados são pouco expressivos em termos de explicação da tipificação. Quanto à variável sexo, a ausência de significância nos permite inferir que não existe diferença relevante entre o comportamento de homens e mulheres com relação ao engajamento partidário. O mesmo resultado foi verificado para estado civil, o que significa que o fato de ser casado não influencia o posicionamento do indivíduo em relação aos partidos políticos, quando considerados ainda seus recursos cognitivos.

Já para idade, verificamos efeitos significativos para três perfis. Os efeitos negativos identificados entre independentes apolíticos e partidários cognitivos indicam que o aumento da idade contribui para que os eleitores deixem de pertencer a tais grupos. Em contrapartida, o passar dos anos está associado ao aumento dos partidários rituais.

A capacidade explicativa de etnia para o perfil de apartidários nos permite inferir que ser branco aumenta em $68,5 \%$ a chance de um indivíduo ser classificado em tal grupo. Em medida ainda mais expressiva, verificamos que residir na área urbana eleva em $242 \% \mathrm{a}$ possibilidade de um eleitor se caracterizar como partidário cognitivo. Essas medidas, consideradas aqui como proxys do status socioeconômico, revelam que esses perfis estão associados à posse de recursos materiais e cognitivos. 
Nesta seção, apresentamos resultados de análises que procuraram avaliar os efeitos do apartidarismo sobre a democracia, por meio da identificação dos possíveis relacionamentos entre os diferentes perfis considerados anteriormente e a manifestação de alguns valores e atitudes políticas. Em termos empíricos, trata-se especificamente de verificar a capacidade preditiva dos perfis do eleitorado sobre medidas que podem ser consideradas como indicadores de uma postura pró-democracia.

Nesse sentido, realizamos cinco diferentes testes: o primeiro, relacionado a valores democráticos, se detém na questão da adesão ao democratismo; o segundo e o terceiro tratam de medidas de competência política e se referem à busca por informação política e ao sentimento de eficácia política subjetiva; e o quarto e o quinto modelos, relacionados à participação cívica e à ação política, apresentam testes multivariados que relacionam o perfil do eleitorado brasileiro com a participação por meio do voto (comparecimento eleitoral) e de atividades de protesto ${ }^{8}$. Considerando nosso objetivo, inserimos nesses modelos as variáveis de controle utilizadas para definição da composição dos perfis (Tabela 4), sobre as quais não nos detemos nesta análise.
[8] Informações descritivas sobre a distribuição percentual dos eleitores entre as variáveis dependentes encontram-se nos Anexos. 
Tabela 5

Preditores de valores, atitudes e comportamentos políticos do eleitorado brasileiro

\begin{tabular}{|c|c|c|c|c|c|c|c|c|c|c|}
\hline \multirow{2}{*}{$\begin{array}{c}\text { Perfis / } \\
\text { Preditores }\end{array}$} & \multicolumn{2}{|c|}{ Democratismo } & \multicolumn{2}{|c|}{$\begin{array}{c}\text { Busca por } \\
\text { informações } 9\end{array}$} & \multicolumn{2}{|c|}{ Eficácia política } & \multicolumn{2}{|c|}{$\begin{array}{l}\text { Comparecimento } \\
\text { eleitoral }\end{array}$} & \multicolumn{2}{|c|}{ Protesto } \\
\hline & B & $\begin{array}{l}\operatorname{Exp}(B) \\
(\text { S. E. })\end{array}$ & B & $\begin{array}{l}\operatorname{Exp}(B) \\
(\text { S. E. })\end{array}$ & B & $\begin{array}{l}\operatorname{Exp}(B) \\
(\text { S. E. })\end{array}$ & B & $\begin{array}{l}\operatorname{Exp}(B) \\
(\text { S. E.) }\end{array}$ & B & $\begin{array}{l}\operatorname{Exp}(B) \\
(\text { S. E. })\end{array}$ \\
\hline \multicolumn{11}{|l|}{ Perfil } \\
\hline Apartidário &, 734 & $\begin{array}{l}2,084^{\star} \\
(, 283)\end{array}$ & ,938 & $\begin{array}{c}2,555^{\star *} \\
(, 235)\end{array}$ & 1,072 & $\begin{array}{c}2,921^{\star *} \\
(, 226)\end{array}$ & 1,226 & $\begin{array}{c}3,408^{*} \\
, 524)\end{array}$ & 1,886 & $\begin{array}{c}6,590^{\star *} \\
(, 359)\end{array}$ \\
\hline $\begin{array}{l}\text { Partidário } \\
\text { cognitivo }\end{array}$ & ,287 & $\begin{array}{l}1,332 \\
(, 283)\end{array}$ & ,886 & $\begin{array}{c}2,425^{\star *} \\
(, 253)\end{array}$ & ,838 & $\begin{array}{l}2,311^{\star} \\
(, 251)\end{array}$ & ,265 & $\begin{array}{l}1,303 \\
(, 374)\end{array}$ & 1,886 & $\begin{array}{c}6,591^{\star *} \\
(, 371)\end{array}$ \\
\hline $\begin{array}{l}\text { Partidário } \\
\text { ritual }\end{array}$ & ,352 & $\begin{array}{l}1,423^{\star} \\
(, 151)\end{array}$ & ,464 & $\begin{array}{c}1,591^{\star *} \\
(, 127)\end{array}$ & ,560 & $\begin{array}{l}1,751^{\star *} \\
(, 139)\end{array}$ &, 532 & $\begin{array}{l}1,702^{*} \\
(, 219)\end{array}$ & ,437 & $\begin{array}{l}1,547 \\
(, 333)\end{array}$ \\
\hline $\begin{array}{c}\text { Sexo } \\
\text { [Masculino] }\end{array}$ &, 187 & $\begin{array}{l}1,205 \\
(, 124)\end{array}$ & ,173 & $\begin{array}{l}1,189 \\
(, 107)\end{array}$ & ,257 & $\begin{array}{l}1,294^{*} \\
(, 121)\end{array}$ &,- 174 & $\begin{array}{c}, 840 \\
(, 167)\end{array}$ & ,473 & $\begin{array}{l}1,605 \\
(, 260)\end{array}$ \\
\hline Idade &, 003 & $\begin{array}{l}1,003 \\
(, 005)\end{array}$ & ,002 & $\begin{array}{l}1,002 \\
(, 004)\end{array}$ & ,002 & $\begin{array}{l}1,002 \\
(, 004)\end{array}$ &, 022 & $\begin{array}{l}1,023^{*} \\
(, 007)\end{array}$ &,- 015 & $\begin{array}{l}\text {,986 } \\
(, 010)\end{array}$ \\
\hline $\begin{array}{c}\text { Etnia } \\
{[\text { Branco] }}\end{array}$ &,- 324 & $\begin{array}{l}, 724^{*} \\
(, 128)\end{array}$ &,- 183 & $\begin{array}{c}, 833 \\
(, 112)\end{array}$ &,- 022 & $\begin{array}{l}, 978 \\
(, 127)\end{array}$ &,- 092 & $\begin{array}{c}, 912 \\
(, 174)\end{array}$ &,- 033 & $\begin{array}{l}, 967 \\
(, 265)\end{array}$ \\
\hline $\begin{array}{l}\text { Estado civil } \\
\text { [Casado] }\end{array}$ & ,401 & $\begin{array}{l}1,494^{*} \\
(, 127)\end{array}$ & , 159 & $\begin{array}{l}1,173 \\
(, 110)\end{array}$ & ,043 & $\begin{array}{l}1,044 \\
(, 126)\end{array}$ & ,558 & $\begin{array}{l}1,748^{*} \\
(, 171)\end{array}$ &,- 479 & $\begin{array}{l}, 620 \\
(, 265)\end{array}$ \\
\hline $\begin{array}{l}\text { Residência } \\
\text { [Área urbana] }\end{array}$ &, 147 & $\begin{array}{l}1,158 \\
(, 196)\end{array}$ & ,373 & $\begin{array}{l}1,452^{\star} \\
(, 166)\end{array}$ & ,240 & $\begin{array}{l}1,271 \\
(, 198)\end{array}$ &, 053 & $\begin{array}{l}1,055 \\
(, 249)\end{array}$ & ,385 & $\begin{array}{l}1,470 \\
(, 482)\end{array}$ \\
\hline Constante &,- 016 & $\begin{array}{c}, 984 \\
(, 450)\end{array}$ & $-1,295$ & $\begin{array}{l}, 274^{*} \\
(, 385)\end{array}$ & $-2,197$ & $\begin{array}{l}111^{\star *} \\
(, 450)\end{array}$ & 953 & $\begin{array}{l}2,594 \\
(, 585)\end{array}$ & $-4,221$ & $\begin{array}{l}, 015^{\star \star} \\
(1,066)\end{array}$ \\
\hline$\%$ de acertos & \multicolumn{2}{|c|}{71,3} & \multicolumn{2}{|c|}{58,5} & \multicolumn{2}{|c|}{72,0} & \multicolumn{2}{|c|}{88,5} & \multicolumn{2}{|c|}{95,3} \\
\hline
\end{tabular}

*sig.<0,050 ** sig. $=0,000$

$\mathrm{n}=1299 ; 1438 ; 1416 ; 1456 ; 1453$

Reference category: Perfil [Independente apolítico].

Change category to Categorical covariate: Indicator ${ }^{10}$.

Fonte: LAPOP (2012).

[9] Foram conduzidas análises de associação entre as variáveis dependentes de alguns modelos. O Gamma entre Interesse por Política e Busca por Informação foi de ,30; e aquele entre Eficácia Política e Interesse por Política foi de, 36 .

[10] A categorização de variáveis independentes a partir da ferramenta Indicator implica a realização de testes internos a partir de sua comparação com dummy das demais categorias da variável. A categoria de referência é omitida do modelo logístico e as demais são contrastadas pela ausência/ presença do atributo referente a cada categoria (Maroco, 2007).
Com relação aos valores democráticos, utilizamos um índice de adesão ao democratismo, composto de variáveis que verificam a consistência da opção pela democracia entre os entrevistados. O resultado indica que o perfil dos eleitores influencia na adesão à democracia, porém apenas quando comparamos os independentes apolíticos com partidários rituais e apartidários. Ambas as comparações indicam que pertencer a um desses tipos de eleitor eleva a razão de chance de apoio à democracia, em $42 \%$ e $108 \%$, respectivamente. Entre os desafetos aos partidos com alta mobilização cognitiva verificamos a maior propensão à manifestação de valores pró-democracia, o que contraria fortemente as hipóteses que associam essa postura crítica à crise de legitimidade do regime como um todo. Portanto, podemos afirmar 
que a desafeição não deve ser imediatamente identificada como sinal de perigo para nossa jovem democracia.

A primeira variável utilizada para mensurar a competência política dos eleitores brasileiros foi a busca por informações pela televisão, pelo rádio, pelos jornais ou pela internet. Adotamos um critério rigoroso de análise, por meio do qual diferenciamos aqueles que declararam informar-se diariamente daqueles que o fazem com menor frequência. O resultado nos permite afirmar que o perfil do eleitor afeta de forma significativa sua busca por informações, de modo que, considerando as demais categorias da variável, ganhos em termos de simpatia partidária e/ou mobilização cognitiva se refletem em aumento da chance de o indivíduo se informar com mais frequência que independentes apolíticos. Em comparação com a categoria de referência, verificamos que partidários rituais possuem aproximadamente $59 \%$ maior razão de chance de buscar informação junto aos veículos de comunicação, ao passo que entre partidários cognitivos e apartidários, que gozam de alta capacidade cognitiva, tais percentuais atingem 142 e 155 pontos, respectivamente. Verificamos assim que o maior efeito potencializador da busca por informação ocorre justamente no perfil dos apartidários, o que pode ser interpretado como segundo indicativo de que essa modalidade de desafeição em relação aos partidos políticos não é acompanhada por alienação política entre os brasileiros, ao menos no que diz respeito a essa dimensão cognitiva do envolvimento político.

A segunda variável de competência política testada refere-se ao sentimento de eficácia política subjetiva, nos termos de Almond eVerba (1989 [1963]). Na onda de 2012 do LAPOP, a questão referente a tal medida tratava da autoavaliação dos brasileiros sobre seu entendimento acerca dos assuntos mais importantes do país. O resultado nos permite afirmar novamente a relevância dos perfis dos eleitores, já que identificamos maior eficácia à medida que os perfis se aproximam daquele que seria ideal nos moldes da teoria da cidadania crítica (Dalton, 2013): a razão de chance de melhores autoavaliações sobre o entendimento de assuntos relevantes para o Brasil aumenta em $75 \%$, $131 \%$ e $192 \%$, respectivamente, entre partidários rituais, partidários cognitivos e apartidários, quando comparados com independentes apolíticos.

Entre as variáveis que tratam da participação, nós nos detivemos inicialmente no comparecimento eleitoral, ou seja, a ação efetiva de votar. Buscamos identificar os preditores do voto entre os brasileiros tomando como variável dependente do modelo multivariado o comparecimento às urnas nas últimas eleições majoritárias, realizadas em 2010. Mais uma vez verificamos a importância do perfil do eleitor, ainda que dessa vez restrita aos partidários rituais e apartidários, cuja classificação aumenta em 70\% e 241\%, respectivamente, a razão de 
chance de tervotado naquela eleição. Novamente, éjustamenteo perfil desafeto e mobilizado o que mais impactou positivamente essa medida de envolvimento político. Aqui, entretanto, a conclusão destoa daquela que derivaria das teses da cidadania crítica, já que, segundo essa perspectiva, a postura questionadora estaria associada à abstenção eleitoral e à busca por formas mais diretas de atuação política. Entre os cidadãos brasileiros a desafeição em relação aos partidos, portanto, não está acompanhada da rejeição do voto como modalidade de participação, o que em hipótese alguma pode ser considerado algo negativo em termos de consolidação democrática.

Com relação aos partidários rituais, entendemos que sua diferenciação com relação aos independentes apolíticos pode ser reflexo do lulismo (Singer, 2012), uma vez que o PT responde pela maior parte dos indivíduos simpáticos a partidos políticos no Brasil, e nos últimos anos tal partido tem mobilizado eleitores com menores renda $e$ escolaridade (Veiga, 2011). Em se tratando dos partidários cognitivos, estes não apresentam maior propensão ao comparecimento eleitoral que eleitores independentes apolíticos. Nesse sentido, tal resultado corrobora a análise de Dalton (2013) acerca do voto dos norte-americanos: diante de condições em que o candidato ou as propostas do partido com o qual simpatizam não sejam as melhores, segundo uma avaliação racional por parte dos partidários cognitivos, estes podem não comparecer às urnas em vez de contribuir para a eleição do candidato que não avaliaram positivamente ou votar em outro partido/candidato. Em que pesem as diferenças com relação ao multipartidarismo brasileiro e a obrigatoriedade do voto no país, supomos que a explicação de Dalton (2013) para o comportamento eleitoral dos americanos se replique, em alguma medida, entre os partidários cognitivos no Brasil.

A última variável testada é a competência cívica no que diz respeito à atuação por meio dos protestos. Nesse sentido, utilizamos a questão do LAPOP 2012 referente à participação em manifestações ou protestos públicos nos últimos doze meses. A análise da medida de atuação não convencional dos brasileiros nos permite inferir que o perfil dos eleitores possui expressiva significância para sua explicação, ao menos quando considerado o conjunto de variáveis incluídas no modelo. Em comparação com independentes apolíticos, verificamos que partidários rituais e apartidários possuem $559 \%$ maior razão de chance de participar de protestos e manifestações. $O$ fato de o protesto ser uma ação política utilizada pelos eleitores partidários e apartidários, ambos com alta mobilização cognitiva, nos permite inferir que elé um repertório de ação política utilizado por eleitores portadores de recursos, como destaca Opp (2009), podendo esses eleitores ter ou não vínculo com os partidos. 


\section{CONSIDERAÇÕES FINAIS}

Os dados apresentados neste artigo ajudam a refletir sobre a relação entre eleitores e partidos políticos no Brasil e, em especial, sobre as consequências do antipartidarismo. Quanto à primeira questão, o que podemos afirmar é que as recentes pesquisas sobre identificação partidária no país não apontam alterações significativas. Se os partidos historicamente foram fracos perante o eleitorado (em termos de lealdade partidária), eles continuam a sê-lo, mas nem por isso se tornaram mais fracos no período recente (Carreirão e Kinzo, 2004; Veiga, 2011). Pelo contrário, o que temos é uma estabilização nos índices de identificação partidária, segundo os próprios resultados do LAPOP apresentados neste artigo, no período compreendido entre 2006 e 2012.

Quanto à segunda questão, resta saber quais os significados e as consequências da não identificação partidária para a democracia. $O$ que nossos dados indicam, corroborando a interpretação de Dalton (2013), é que temos dois tipos de não identificação partidária no país. Há o grupo dos independentes apolíticos, formado por eleitores com baixa mobilização cognitiva e sem identificação partidária, os quais possuem correlatos atitudinais e comportamentais pouco compatíveis com as exigências normativas da democracia, ou seja, em comparação com os demais perfis de eleitores, possuem baixa informação política, baixo sentimento de eficácia política, são os que menos comparecem às eleições e os que menos protestam, além de terem baixa adesão à democracia perse.

Esse eleitorado tem declinado ao longo das últimas três rodadas do LAPOP, estando hoje em níveis semelhantes àqueles verificados na pesquisa de 2006. Importante também destacar que o declínio dos independentes apolíticos se deu num padrão inferior ao incremento da escolaridade média do brasileiro, ou seja, o aumento da escolarização não tem se refletido necessariamente em ganhos de interesse político e identificação partidária; portanto, em mobilização cognitiva. O problema é que esse eleitor corresponde hoje a mais de $60 \%$ do eleitorado nacional, enquanto nos EUA esse contingente não ultrapassava 13 pontos percentuais em 2008. Dados agregados do European Social Survey para a parte ocidental do continente indicam que em 2002 esse percentual atingiu pouco mais de 30 pontos. Ainda que esses dados se refiram a períodos distintos, servem como parâmetros para a comparação e colocam a nossa situação como bastante distinta (Dalton, 2013).

Quanto ao segundo tipo de apartidário (aquele com alta mobilização cognitiva), apesar de corresponder a apenas $6,3 \%$ do eleitorado em 2012, não estamos tão distantes do padrão internacional, já que 
[11] Os percentuais de partidários rituais nos Estados Unidos e na Europa atingem cerca de $24 \%$ e $20 \%$ do eleitorado, respectivamente, próximos ao percentual identificado no Brasil. Entretanto, no cenário nacional o contingente de indivíduos concentrados nos perfis de baixa cognição se aproxima de $90 \%$, diante de $42 \%$ dos norte-americanos e $51 \%$ dos europeus. Entendemos, assim, que não é o percentual de partidários rituais o maior problema do Brasil, mas a alta concentração de eleitores nos perfis com menor cognição. nos EUA, em 2008, Dalton (2013) verificou a existência de $19 \%$ e os dados europeus registram pouco mais de $10 \%$. Em termos de correlatos atitudinais e comportamentais, esse é o eleitor mais próximo às exigências normativas da democracia, pois é o mais informado, o que demonstra maior sentimento de eficácia política, o que mais vota e o que mais protesta. Além disso, é também aquele eleitor que apresenta maior adesão à democracia entre todos os perfis estudados. Nesse sentido, considerando o eleitor em questão, falta de identificação partidária não pode ser considerada um indicador de crise de representação ou mesmo de crise da democracia, mas de eleitores que se relacionam com outras instituições (que não os partidos) para exercer sua cidadania política. Trata-se, nesse caso, do "cidadão crítico" descrito por Dalton, Inglehart, Norris, entre outros.

Podemos afirmar, então, que a não identificação partidária é um fenômeno multidimensional, já que temos aqueles sem identificação que apresentam padrões atitudinais e comportamentais típicos da ideia de alienação política (Reef e Knoke, 1999) e também os que se aproximam do ideal do "cidadão crítico". O problemaéque a distribuição de nosso eleitorado é majoritariamente dominada pelo primeiro perfil, o que coloca a alienação política no centro do diagnóstico de nossa democracia.

Preocupante também é o fato de que o segundo perfil que concentra maior número de eleitores é o partidário ritual ${ }^{11}$, perfil muito próximo àquele descrito por Fábio Wanderley Reis (2000) através da denominação "síndrome do Flamengo", ou seja, um eleitor com baixos recursos e baixa capacidade de decodificar o mundo da política para além de imagens binárias e toscas do quadro político-partidário, que tem sua forma mais visível na distinção entre "partido dos ricos" e "partido dos pobres".

Em síntese, no que diz respeito a nossa democracia, o problema não reside no apartidarismo ou no desencanto com as instituições representativas tradicionais, pois essa postura pode ser acompanhada de atitudes e valores congruentes com o aprimoramento dessa forma de governo. O problema que permanece como ameaçadoré a alienação política ou a falta de sofisticação política de um contingente majoritário de brasileiros, desmobilizado em termos cognitivos e/ou orientado por noções muito rudimentares sobre o mundo da política. 
Informações técnicas das variáveis

Escolaridade [2006]

[VS2] Até que série o(a) sr.(a) estudou?

Codificação: $1=$ Analfabeto/Sem instrução

$2=$ Primeiro ano do Ensino Fundamental

$3=$ Segundo ano do Ensino Fundamental

$4=$ Terceiro ano do Ensino Fundamental

5= Quarto ano do Ensino Fundamental incompleto

$6=$ Quarto ano do Ensino Fundamental/Primário completo

7= Quinta série/Primeiro ano Ginásio

$8=$ Sexta série/Segundo ano Ginásio

$9=$ Sétima série/Terceiro ano Ginásio

10 = Oitava série incompleta/Quarto ano Ginásio incompleto

1l= Oitava série/Quarto ano Ginásio/Primeiro Grau completo

$12=$ Primeiro ano do Ensino Médio/Primeiro ano do Segundo Grau

$13=$ Segundo ano do Ensino Médio/Segundo ano do Segundo Grau

14= Terceiro ano do Ensino Médio/ Segundo Grau incompleto

15= Terceiro ano do Ensino Médio/ Segundo Grau completo

16= Iniciou faculdade/universidade mas não se formou

$17=$ Graduação/faculdade

$18=$ Mestrado

$19=$ Doutorado

$20=$ Lato sensu

$21=$ Pós - Doutorado

Recodificação: $1=$ Até Ensino Fundamental completo [ 1 a 11 ]

$2=$ Até Ensino Médio completo [12 a 15]

$3=$ Ensino pós-Médio ou Superior incompleto [16]

$4=$ Ensino Superior completo ou Pós-graduação [17

a 21$]$

Escolaridade [2008/2010/2012]

[ed] Qual foi o último ano de educação que você completou ou foi aprovado?

Codificação: Aberta 
Recodificação: $1=$ Até Ensino Fundamental completo (o a 8 anos de estudo)

2= AtéEnsino Médio completo (9 a 11 anos deestudo) 3= Ensino pós-Médio ou Superior incompleto (12 a 14 anos de estudo)

$4=$ Ensino Superior completo ou Pós-graduação

( 15 ou mais anos de estudo)

Interesse por política [2006/2008/2010/2012]

[polı] Quanto interesse você tem pela política: muito, algum, pouco ou nenhum?

Codificação: $1=$ Muito

2 = Algum

$3=$ Pouco

$4=$ Nenhum

Recodificação: $1=$ Nenhum

$2=$ Pouco

$3=$ Algum

$4=$ Muito

Mobilização cognitiva [2006/2008/2010/2012]

Índice somatório das variáveis escolaridade e interesse por política, ambas recodificadas.

Codificação: $\quad 2=$ Baixa mobilização cognitiva

$3=3$

$4=4$

$5=5$

$6=6$

$7=7$

$8=$ Alta mobilização cognitiva

Recodificação: $1=$ Baixa [2 a 5$]$

$$
2=\operatorname{Alta}[6 \text { a } 8]
$$

Simpatia partidária $[2006 / 2008 / 2010 / 2012]$

[vbıo] Neste momento, simpatiza com algum partido político?

Codificação: $\quad 1=\operatorname{Sim}$

$$
2=\mathrm{Não}
$$

Recodificação: $1=$ Não

$$
2=\operatorname{Sim}
$$

\section{Independente apolítico [2006/2008/2010/2012]}

Combinação entre variáveis mobilização cognitiva e simpatia partidária. Perfil: mobilização cognitiva = 1 e simpatia partidária $=1$ 


\section{Partidário Ritual [2006/2008/2010/2012]}

Combinação entrevariáveis mobilização cognitiva e simpatia partidária.

Perfil: mobilização cognitiva $=1$ e simpatia partidária $=2$

\section{Partidário Cognitivo [2006/2008/2010/2012]}

Combinação entrevariáveis mobilização cognitiva e simpatia partidária.

Perfil: mobilização cognitiva $=2$ e simpatia partidária $=2$

\section{Apartidário [2006/2008/2010/2012]}

Combinação entrevariáveis mobilização cognitiva e simpatia partidária.

Perfil: mobilização cognitiva = 2 e simpatia partidária $=1$

$$
\begin{aligned}
& \text { Sexo [2012 }] \\
& \begin{aligned}
& \text { [q1] Gênero } \\
& \text { Codificação: } 1=\text { Homem } \\
& 2=\text { Mulher } \\
& \text { Recodificação: } 1=\text { Feminino } \\
& 2=\text { Masculino }
\end{aligned}
\end{aligned}
$$

\section{Idade [2012]}

[q2] Qual a sua idade em anos completos?

Codificação: Aberta

Recodificação:Sem necessidade.

\section{Etnia [2012]}

[etid] Você se considera uma pessoa branca, mestiça, indígena, negra, mulata ou outra?

$$
\begin{aligned}
& \text { Codificação: } \text { 1= Branco } \\
& 2=\text { Mestiço } \\
& 3=\text { Indígena } \\
& 4=\text { Negro } \\
& 5=\text { Mulato } \\
& 6=\text { Moreno } \\
& 7=\text { Outro } \\
& 9=\text { Chinês } \\
& 10=\text { Indiano } \\
& 11=\text { Javanês } \\
& 12=\text { Quilombola }
\end{aligned}
$$

Recodificação: $\mathrm{O}=$ Não branco

$$
1=\text { Branco }
$$

Estado civil [2012]

[q11] Qual é seu estado civil? 
Codificação: $\quad 1=$ Solteiro

$2=$ Casado

$3=$ União livre

$4=$ Divorciado

$5=$ Separado

$6=$ Viúvo

Recodificação: $\mathrm{O}=$ Não casado

$\mathbf{l}=$ Casado

Área de residência [2012]

[ur] Âmbito

Codificação: $\quad 1=$ Urbano

$2=$ Rural

Recodificação: $1=$ Rural

$2=$ Urbano

Democratismo [2012]

[dem2] Com qual das seguintes frases você está mais de acordo:

Codificação: $\quad 1=$ Para pessoas como eu, tanto faz um regime democrático como um não democrático

2= Ademocracia é preferível a qualquer outra forma de governo

3= Em algumas circunstâncias um governo autoritário pode ser preferível a um democrático

Recodificação: $O=$ Não democrático [ 1 e 3 3]

$1=$ Democrático $[2]$

[demı1] Vocêcrê que em nosso país faz falta um governo de pulso firme?

Codificação: $\quad 1=$ Pulso firme

$2=$ Participação de todos

Recodificação: $0=$ Não democrático $[1]$

$1=$ Democrático $[2]$

[ing4] Pode ser que a democracia tenha problemas, mas é melhor do que qualquer forma de governo.

Codificação: $1=$ Discorda totalmente

$2=2$

$3=3$

$4=4$

$5=5$

$6=6$

$7=$ Concorda totalmente 
Recodificação: $\mathrm{O}=$ Não democrático $[1$ a 3$]$

$1=$ Algo democrático [4]

$2=\operatorname{Democrático~}[5$ a 7$]$

O índice de democratismo foi construído pela somatória das acima descritas, ambas recodificadas.

Codificação: $\quad \mathrm{O}=$ Não democrático

$1=1$

$2=2$

$3=$ Democrático

Recodificação: $\mathrm{O}=$ Baixo democratismo $\left[\begin{array}{lll}0 & \text { e }\end{array}\right]$

$\mathrm{I}=$ Alto democratismo [ 2 e 3$]$

\section{Busca por informação sobre política [2012]}

[gio] Com que frequência segue as notícias, seja pela televisão, pelo rádio, pelo jornal ou pela internet?

Codificação: $1=$ Diariamente

$2=$ Algumas vezes por semana

$3=$ Algumas vezes ao mês

$4=$ Raramente

$5=$ Nunca

Recodificação: $\mathrm{O}=$ Baixa [2 a 5$]$

$\mathrm{l}=\operatorname{Alta}[1]$

Eficácia política subjetiva

[eff2] Você sente que entende bem os assuntos políticos mais importantes do país?

Codificação: $\quad 1=$ Muito em desacordo

$2=2$

$3=3$

$4=4$

$5=5$

$6=6$

$7=$ Muito de acordo

Recodificação: $O=$ Baixa [ 1 a 4 ]

$1=\operatorname{Alta}[5$ a 7$]$

Comparecimento eleitoral [2012]

[vb2] Votou nas últimas eleições presidenciais?

Codificação: $1=$ Sim

$2=$ Não

Recodificação: $\mathrm{O}=\mathrm{Não}$

$1=\operatorname{Sim}$ 


\section{Protesto [2012]}

[prot3] Nos últimos 12 meses, participou de manifestação ou protesto público?

Codificação: $\quad 1=$ Sim, participou

$2=$ Não participou

Recodificação: $\mathrm{O}=$ Não participou

$\mathrm{l}=$ Participou

\section{ANEXOS}

Caracterização sociodemográfica dos eleitores brasileiros em 2012

\begin{tabular}{|c|c|c|c|c|c|c|}
\hline \multicolumn{2}{|c|}{ Variáveis/categorias } & Independentes & $\begin{array}{l}\text { Partidários } \\
\text { Bituais }\end{array}$ & Partidários & Apartidários & TOTAL \\
\hline \multirow{2}{*}{ Sexo } & Feminino & $182(32 \%)$ & $37(12,4 \%)$ & $47(2,5 \%)$ & $47(3,2 \%)$ & $735(50,1 \%)$ \\
\hline & Masculino & $459(31,3 \%)$ & $188(12,8 \%)$ & $40(2,7 \%)$ & $45(3,1 \%)$ & $732(49,9 \%)$ \\
\hline \multirow{4}{*}{ Idade $^{*}$} & $\begin{array}{c}\text { De } 16 \text { a } 29 \\
\text { anos }\end{array}$ & $320(21,8 \%)$ & $107(7,3 \%)$ & $35(2,4 \%)$ & $29(2 \%)$ & $491(33,5 \%)$ \\
\hline & $\begin{array}{c}\text { De } 30 \text { a } 44 \\
\text { anos }\end{array}$ & $336(22,9 \%)$ & $110(7,5 \%)$ & $29(2 \%)$ & $35(2,4 \%)$ & $511(34,8 \%)$ \\
\hline & $\begin{array}{c}\text { De } 45 \text { a } 59 \\
\text { anos }\end{array}$ & $202(13,8 \%)$ & $104(7,1 \%)$ & $9(0,6 \%)$ & $25(1,7 \%)$ & $340(23,2 \%)$ \\
\hline & $\begin{array}{c}60 \text { anos ou } \\
\text { mais }\end{array}$ & $70(4,8 \%)$ & $47(3,2 \%)$ & $4(0,3 \%)$ & $3(0,2 \%)$ & $125(8,5 \%)$ \\
\hline \multirow{2}{*}{ Etnia } & Não branco & $606(41,3 \%)$ & $248(16,9 \%)$ & $38(2,6 \%)$ & $48(3,3 \%)$ & $940(64,1 \%)$ \\
\hline & Branco & $324(22,1 \%)$ & $122(8,3 \%)$ & $37(2,5 \%)$ & $44(3 \%)$ & $527(35,9 \%)$ \\
\hline \multirow{2}{*}{ Estado civil } & Não casado & $381(26 \%)$ & $154(10,5 \%)$ & $35(2,4 \%)$ & $32(2,2 \%)$ & $603(41,1 \%)$ \\
\hline & Casado & $547(37,3 \%)$ & $216(14,7 \%)$ & $41(2,8 \%)$ & $60(4,1 \%)$ & $864(58,9 \%)$ \\
\hline \multirow{2}{*}{ Área de residência } & Rural & $125(8,5 \%)$ & $44(3 \%)$ & $3(0,2 \%)$ & $7(0,5 \%)$ & $179(12,2 \%)$ \\
\hline & Urbana & $804(54,8 \%)$ & $326(22,2 \%)$ & $73(5 \%)$ & $85(5,8 \%)$ & $1288(87,8 \%)$ \\
\hline
\end{tabular}

$\mathrm{n}=1467$

Fonte: LAPOP (2012).

* Utilizada nos testes como variável escalar. As faixas etárias são utilizadas nesta tabela somente como informação da distribuição do eleitorado nos distintos perfis. 


\begin{tabular}{|c|c|c|c|c|}
\hline & & Etnia & Idade & Escolaridade \\
\hline \multirow{3}{*}{ Etnia } & Pearson Correlation & 1 & & \\
\hline & Sig. (2-tailed) & & & \\
\hline & $\mathrm{N}$ & 1495 & & \\
\hline \multirow{3}{*}{ Idade } & Pearson Correlation &,- 001 & 1 & \\
\hline & Sig. (2-tailed) & ,982 & & \\
\hline & $\mathrm{N}$ & 1495 & 1500 & \\
\hline \multirow{3}{*}{ Escolaridade } & Pearson Correlation &, $184^{* *}$ &,$- 239^{* *}$ & 1 \\
\hline & Sig. (2-tailed) &, 000 &, 000 & \\
\hline & $\mathrm{N}$ & 1495 & 1500 & 1500 \\
\hline
\end{tabular}

**. Correlation is significant at the 0.01 level (2-tailed).

Fonte: LAPOP (2012).

Valores, atitudes e comportamentos dos políticos brasileiros em 2012 (\%)

Independentes apoliticos

Democratismo $(n=1306)$

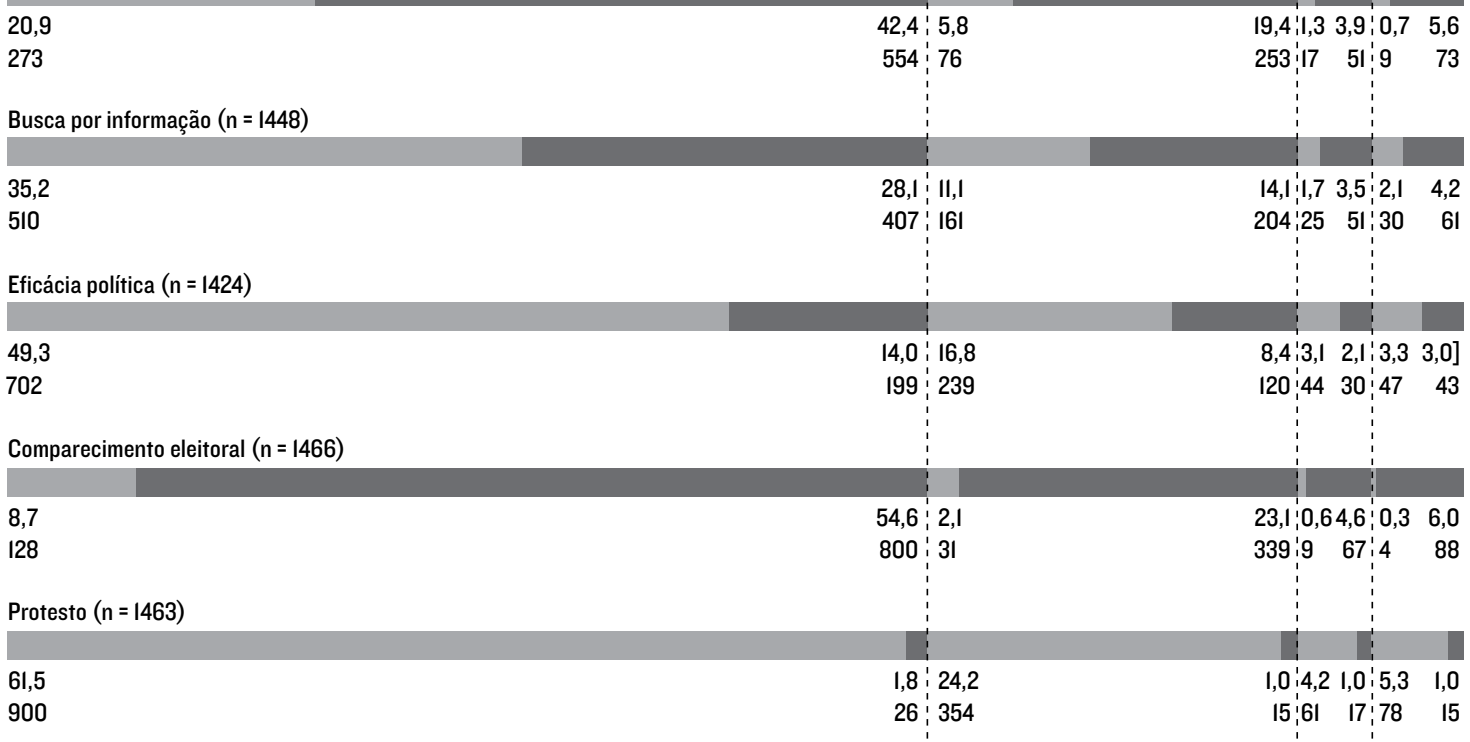

Legenda: Ausência do atributo Presença do atributo

Onde: Pcong. = Partidários cognitivos; Apart. = Apartidários

Fonte: LAPOP (2012) 


\section{REFERÊNCIAS BIBLIOGRÁFICAS}

Alaminos, A., e Penalva, C. The cognitive mobilization index: crises and political generations. Sage Open. Disponível em 〈http://sgo.sagepub. com/content/early/2012/o2/28/2158244012440437>. Acesso em 27/5/2012.

Almond, G.A., eVerba, S.The civic culture:political attitudes and democracy in five nations.3.ed. Nova York: Sage, 1989 [1963].

Avelar, L. "Participação política”. In: Avelar, L., e Cintra, A.O. Sistemapolítico brasileiro:uma introdução. Rio de Janeiro/São Paulo: Fundação Konrad Adenauer/Unesp, 2004.

Baquero, M. Avulnerabilidade dos partidos politicos e a crise da democracia na América Latina. Porto Alegre: UFRGS, 2000.

Borba, J., e Ribeiro, E.A. "Participação convencional e não convencional na América Latina”. In:Baquero, M.(org.).Cultura(s) políticas(s) e democracia no século XXI na América Latina. Porto Alegre:UFRGS, 2011.

Carreirão, Y. de S. "Opiniões públicas e sentimentos partidários dos eleitores brasileiros”. Opinião Pública. Campinas, v. 14, nº 2, pp. 319-351, 2008.

. "Relevant factors for the voting decision in the 2002 presidential election: an analysis of the ESEB (Brazilian Electoral Study) Data". Brazilian Political Science Review, v. 1, $\mathrm{n}^{\circ}$ 1, pp. 70-101, 2007.

. A decisão do voto nas eleições presidenciais brasileiras. Florianópolis/Rio de Janeiro: UFSC/FGV, 2002.

Carreirão, Y. de S., e Kinzo, M.D. "Partidos políticos, preferência partidária e decisão eleitoral no Brasil (1989-2002)". Dados, v. 47, no 1, pp.131-168, 2004.

Catterberg, G. "Evaluations, referents of support, and political action in new democracies". International Journal of Comparative Sociology. Thousand Oaks, v. 44, pp.173-198, jun. 2003.

Dalton, R.J.The apartisan American: dealignment and changing electoral politics. Washington, DC: Sage, 2013.

.Citizen politics:public opinion and political parties in advanced industrial democracies. 5.ed. Washington, DC: CQ 2008.

. "Partisan mobilization, cognitive mobilization and the changing American electorate". Electoral Studies, $n^{\circ} 26, \mathrm{pp}$. 274-286, 2007 .

. "Citizenship norms and political participation in America: the good news is... the bad news is wrong". Occasional Paper Series, $\mathrm{n}^{\circ} 1,2006$.

. "Cognitive mobilization and partisan dealignment in advanced industrial democracies". Journal of Politics, $\mathrm{n}^{\circ} 46, \mathrm{pp}$. 264-284, 1984 . 
Dalton, R.J., Mcallister, I., e Wattenberg, M.P. “Democracia e identificação partidária nas sociedades industriais avançadas". Análise Social, v. 38, nº 167, pp. 295-320, 2003.

Dalton, R. J., e Wattenberg, M.P. Parties without partisans: political change in advanced industrialized democracies. Oxford: Oxford University Press, 2002.

Della Porta, D. Introdução a ciência política. Lisboa: Estampa, 2003.

Inglehart, R. Culture shift in advanced industrial society. Princeton: Princeton University Press, 1990.

Inglehart, R., e Catterberg, G. "Trends in political action: the development trend and the post-honeymoon decline". International Journal of Comparative Sociology. Thousand Oaks, v.43, n $\mathrm{n}^{\mathrm{O}}$ 3-5, pp.300-316, out. 2002.

Kinzo, M.D.G. "Os partidos no eleitorado: percepções políticas e laços partidários”.In:Kinzo, M.D.G.,e Braga,M.doS.S.(orgs.).Eleitores e representação partidária no Brasil. São Paulo: Humanitas, 2007.

Mair, P. "Os partidos políticos e a democracia".Análise Social, v. 38 , $\mathrm{n}^{\mathrm{0}}$ 167, pp. 277-293, 2003.

Maroco, J.Análise estatística com utilização do SPSS. 3. ed. Lisboa: Silabo, 2007 .

Mayer, R. Os partidos como organizações: um estudo comparado do PSDB E PT. 2011.86 f. Dissertação de mestrado. Programa de Pós-Graduação em Ciência Política, UFPR, Curitiba, 2011.

Milbrath, L., e Goel, M.L. Political participation. Boston: University of America, 1965.

Norris, P. "Political activism: new challenges, new opportunities". In: BOIX, C., e Stokes, S.C. The Oxford handbook of comparative politics. Oxford: Oxford University Press, 2007. .A virtuous circle: political communications in postindustrial societies. Cambridge: Cambridge University Press, 2000.

O'Neill, B. "Generational patterns in the political opinions and behaviour of Canadians". Policy Matters. Montreal,v. 2, n 5, 2001.

Opp, K.D. Theories of political protest and social movements: a multidisciplinary introduction, critique, and synthesis. Londres: Routledge, 2009.

Putnam, R. (org.).El declive del capital social. Barcelona: Galaxia Gutenberg, 2003.

Reis, F. W.Mercado e utopia: teoria politica e sociedade brasileira. São Paulo: USP, 2000.

Reis, F.W., e Castro, M.M.M. de. "Regiões, classe e ideologia no processo eleitoral brasileiro". Lua Nova. São Paulo, no 26, pp. 81-131, 1992.

Reef, M.J., e Knoke, D. "Political alienation and efficacy". In: Reef,J. P., Shaver, P.R., e Wrightsman, L.S. (eds.). Measures of political attitudes. Nova York:Academic, 1999. 
Recebido para publicação em 26 de abril de 2015.

\section{NOVOS ESTUDOS}

CEBRAP

101, março 2015

pp. $27-55$
Ribeiro, E.A. “Confiança política na América Latina: evolução recente e determinantes individuais". Revista de Sociologia e Política. Curitiba, v. 19, pp. 167-182, 2011.

."Cultura política e gênero no Brasil:estudo exploratório sobre as bases da sub-representação feminina". In: Baquero, M. (org.).Cultura(s) políticas(s)e democracia no século XXI na América Latina. Porto Alegre: UFRGS, 2011 .

Ribeiro, E.A., Carreirão, Y. de S., e Borba, J. “Sentimentos partidários e atitudes políticas entre os brasileiros". Opinião Pública. Campinas, v. $17, \mathrm{n}^{\circ}$ 2, pp. 333-368, nov. 2011.

Samuels, D. J., e Zucco Junior, C. "The power of partisanship in Brazil: evidence from survey experiments". Social Science Research Network, out. 2012. Disponível em «http://papers.ssrn.com/sol3/papers. cfm?abstract_id=1903312>. Acesso em 23/6/2013.

Singer, A. Os sentidos do lulismo. Reforma gradual e pacto conservador. São Paulo: Companhia das Letras, 2012.

Torcal, M., e Montero, J.R. (orgs.). Political disaffection in contemporary democracies:social capital, institutions and politics. Londres: Routledge, 2006.

Van Biezen, I., Mair, P., e Poguntke, T. “Going, going,... gone? The decline of party membership in contemporary Europe". European Journal of Political Research, $\mathrm{n}^{\circ}$ 51, pp. 24-56, 2012.

Veiga, L. F. “O partidarismo no Brasil (2002/2010)". Opiniño Pública, Campinas, v. $17, \mathrm{n}^{\circ} 2$, pp.400-425, nov. 2011.

."Os partidos brasileiros na perspectiva dos eleitores: mudanças e continuidades na identificação partidária e na avaliação das principais legendas após 2002 ". Opinião Pública. Campinas, v. 13, $\mathrm{n}^{\circ} 2$, pp. 340-365, nov. 2007.

Welzel, C., Inglehart, R., e Deutsch, F.S. “Social capital, voluntary associations and collective action: which aspects of social capital have the greatest 'civic' payoff?". Journal of Civil Society. Londres, v. 1, $\mathrm{n}^{\circ}$ 2, pp. 121-146, set. 2005.

Witheley, P. "Is the party over? The decline of party activism and membership across the democratic world". Party Politics, v. 17, n⿳ 21, 2011.

Julian BORBA é doutor em Ciência Política pela Universidade Federal do Rio Grande do Sul e docente do Programa de Pós-Graduação em Sociologia Política da Universidade Federal de Santa Catarina.(julian@cfh.ufsc.br)

Éder Rodrigo Gimenes é doutorando em Sociologia Política pela Universidade Federal de Santa Catarina e mestre em Ciências Sociais pela Universidade Estadual de Maringá. (ergimenes@ uem.br)

EDNALDO APARECIDO RIBEIRO é doutor em Sociologia pela Universidade Federal do Paraná e docente dos Programas de Pós-Graduação em Ciências Sociais da Universidade Estadual de Maringá e de Ciência Política da Universidade Federal do Paraná.(ednaldorip@uol.com.br) 